\title{
Identification of disaster risks in spatial planning for sustainable development: a case study in Kosovo
}

\author{
M. Yokota \& G. Seneque \\ United Nations Human Settlements Programme (UN-HABITAT), Kosovo
}

\begin{abstract}
Kosovo has and is facing an unprecedented construction boom and growth of urban areas. Unfortunately, this growth is not adequately controlled and managed by the government, particularly the new political situation after the conflict and major economic changes that have triggered population migrations from rural areas to cities and throughout Kosovo in general. However, the cities are not prepared for such sudden influx of population. In addition, due to the lack of proper development control and disaster risk assessment and management, vulnerability to natural disasters in urban areas has considerably increased, which will undermine the sustainable growth of the cities in Kosovo.

This paper explores how the risks of natural disasters are addressed in national policies and spatial planning in Kosovo and through a case study it is unveiled that the tendency is for areas vulnerable to natural disasters to be undergoing expansion. Throughout the analysis, practical approaches for disaster risk reduction and mitigation are introduced from a spatial planning perspective.
\end{abstract}

Keywords: developing countries, natural disaster, housing, disaster risk assessment and management, risk reduction, mitigation.

\section{Introduction}

Since the conflict ended in June 1999, Kosovo has been facing an unprecedented construction boom and growth of urban areas, which is not adequately controlled by the Kosovo self-governments. The new political situation after the conflict and major economic changes has resulted in population migration from rural areas to cities and throughout Kosovo in general. However, the cities are not prepared for such an influx of population and the lack of a legitimate spatial plan 
and development control accelerate chaotic developments, both in terms of housing and commercial developments.

In 2003, the "Law on Spatial Planning" was formulated that obliges municipalities to draft Municipal and Urban Development Plans (MDP/UDP); nevertheless the major constraint of limited numbers of planning staff in the municipalities has brought about a severe delay in the planning process. In 2005 , UN-HABITAT Kosovo, funded by the Swedish government (SIDA), launched the "Municipal Spatial Planning Support Program" to support drafting MDP/UDP in the duty municipalities where six of the secondary cities are located.

As a consequence, four out of six duty municipalities had finalized their MDP/UDP's by the beginning of 2009, and some of the other smaller municipalities have also requested the support of UN-HABITAT in the second phase of the program.

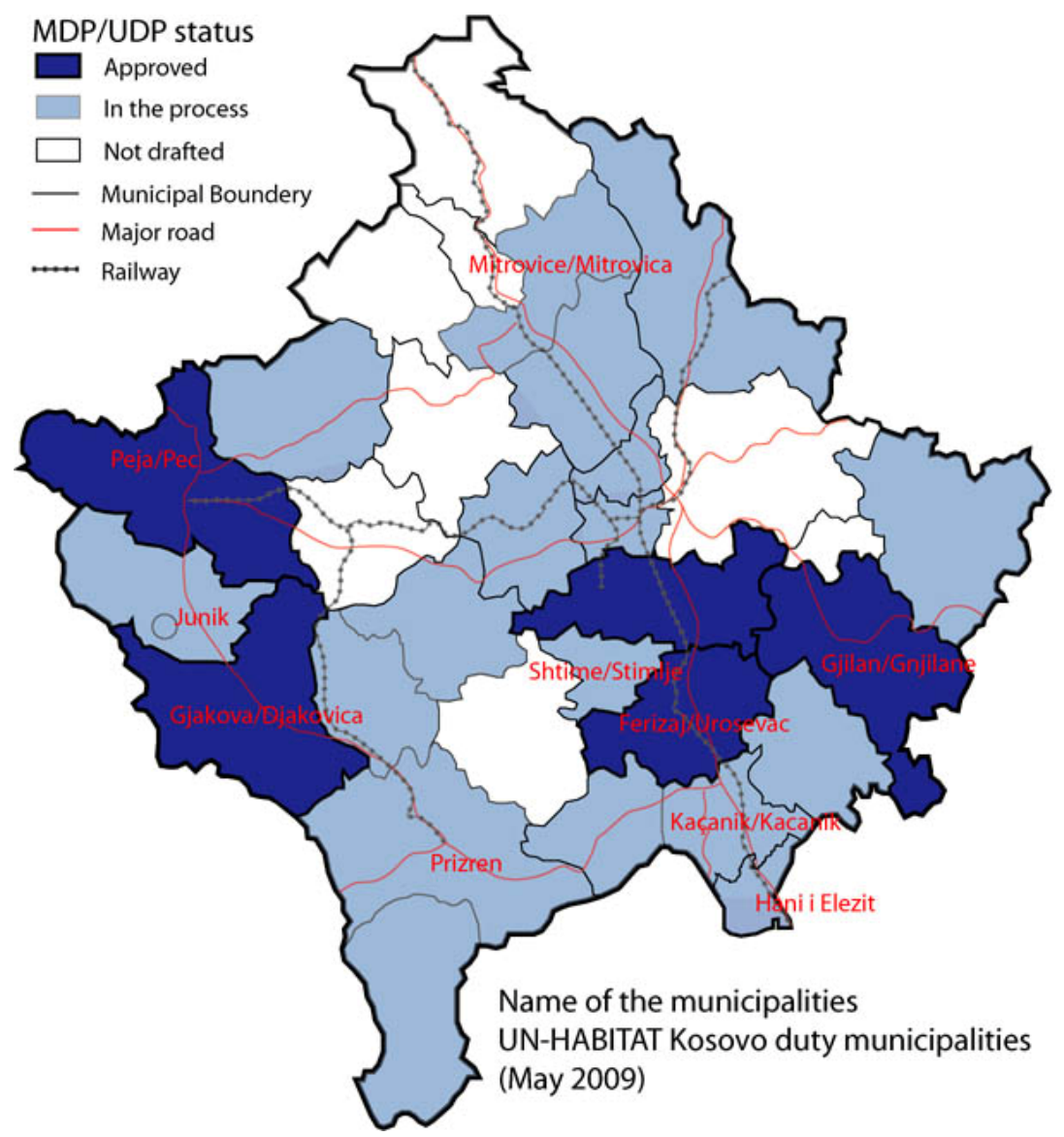

Figure 1: $\quad$ MDP/UDP drafting process in the Kosovo municipalities. 
Recently there has been an increased awareness of spatial planning but the quality of the plans produced is not adequate; however, the MDP/UDP's have been approved for the first time by the new self-government. In Kosovo, most public investments that are prioritized in spatial plans are closely related to economic development and basic urban infrastructure provision e.g. water, sewage, electricity, roads and public facilities.

However these developments cannot be achieved in a sustainable manner without proper consideration to the location, i.e. where it is not only convenient but also adequately secured from disasters, since large numbers of natural disasters have occurred in Kosovo, e.g. earthquake, flood, landslide, forest fire and erosion. In addition, due to a lack of information on high disaster risk areas, people construct housing in the disaster prone areas and often suffer from severe damages. For sustainable growth of the urban areas in Kosovo that are facing an influx of population, it is inevitable to take into account disaster risks in spatial planning.

In previous studies, Wamsler [1] conceptualised the role of urban planning for disaster risk reduction and El-Masri [2] studied the methods to minimize vulnerability to natural disasters in developing countries for sustainable development. The results of other studies [3-6] also show the various approaches to risk reduction and mitigation in the pre-disaster period.

This paper explores how disaster risks are treated in national policies and spatial planning in Kosovo as a case study in developing countries. Through a case study, it is unveiled that the tendency is for areas vulnerable to natural disasters to be undergoing expansion. Throughout the analysis, practical approaches for disaster risk reduction and mitigation are introduced from a spatial planning perspective.

\section{Policies for spatial planning and natural disasters}

The Ministry of Environment and Spatial Planning (MESP) is in charge of spatial planning and the Ministry of Internal Affairs (MIA) is in charge of disaster issues at a central level. The Institute of Seismology in the Ministry of Energy and Mining (IS/MEM) is responsible for monitoring earthquakes while crucial geological data is owned by the Ministry. The Law on Spatial Planning and the Law for protection against natural and other disasters are fundamental legal documents in this aspect.

Since Kosovo is UN administration territory, there is a UN Kosovo Team (UNKT), which consists of international organizations in Kosovo and is also dealing with natural disaster issues in collaboration with the MIA. The UNKT coordinates responsibilities for international agencies in Kosovo for disaster response.

\subsection{Spatial planning}

The Law on Spatial Planning describes five different levels of plan. The MESP is responsible for drafting the Spatial Plan of Kosovo, which identifies long-term 
principles and goals of spatial planning for the entire territory of Kosovo for the period of at least ten years. The final draft of the plan was submitted to the parliament in 2006; nevertheless it has not been approved yet. The MESP is also responsible for Spatial Plans for Special Areas to identify natural conservation areas.

Municipalities are obliged to draft a MDP that describes the objectives of economic, social and spatial developments for the period of at least five years. They are also obliged to draft an UDP that shall be prepared in urban areas for identifying projections for development and management of urban areas for the period of at least five years, in order to achieve balanced and sustainable spatial development. As a detailed plan, they can draft an Urban Regulatory Plan, which defines the conditions for regulation of space as well as rules for the location of buildings on urban land plots.

Regarding the law and its instructions, the aspect of natural disasters are not clearly mentioned in the components of the plans. However, the Spatial Plan of Kosovo, for instance, comprises a general description of natural disaster risks e.g. earthquake, flood, landslide and erosion.

\subsection{Natural disasters}

The main task of Law for protection against natural and other disasters is to provide the framework for protection and rescue against disasters. The MIA is the responsible body for drafting a contingency plan for disasters and all ministries are obliged to provide any information that can contribute for drafting the plan.

On the instruction of the law, municipalities set up a department of emergency in close cooperation with fire brigades. The department deals with not only natural disasters, but also other disasters, such as traffic accidents, building fires and influences of natural contaminations .All cases of disasters are reported to the MIA every month. An emergency call centre is also formulated within municipalities for disaster response.

Disaster risk assessment is one of the crucial components of the law. The first risk assessment survey was implemented in 2000. In 2009, the following survey has been started and staff training for the risk assessment is provided by the MIA as well. The contents of the risk assessment particularly describe the past experiences of disasters and identify the location and impacts.

As the whole strategy of natural disasters is strongly related to post-disaster response, disaster risk assessment is merely used for drafting the contingency plan at the policy level. Hence there is no substantial cooperation between the MIA and the IS/MEM, while earthquake information is useful for disaster reduction rather than post-disaster response.

Regarding disaster reduction in the field, some municipalities implemented projects for urgent risk reduction, for instance, flood prone areas were identified from their experiences and public infrastructure, such as the canal and sewage network, has been improved for risk reduction. 


\section{Expansion of disaster vulnerability}

The UN/ISDR [7] reviewed experiences of natural disasters in South Eastern Europe and examined the probability of natural disasters in each country within the region. According to the study, the flood risk in Kosovo is considerably higher than other parts of the region. In addition, earthquake risk should not be over looked due its enormous impact, even when the probability is estimated at approximately once in 15 years. For instance, Skopje city, the capital of Former Yugoslav of Macedonia, which is located just a few kilometres from the territory of Kosovo, experienced a magnitude 6.1 earthquake in 1963 that destroyed approximately $40 \%$ of the city. There were 1,300 casualties and 4,000 people were injured.

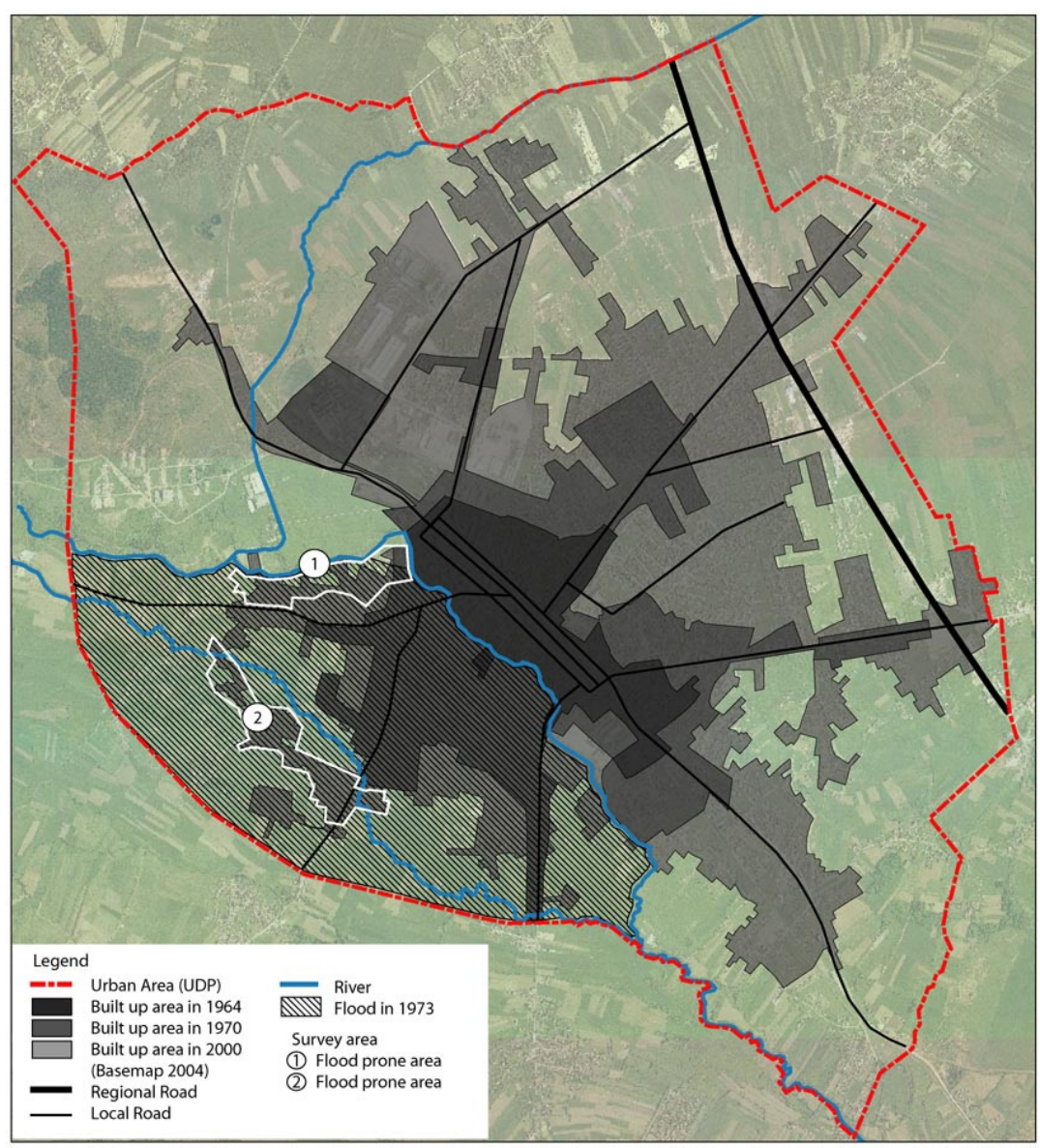

Figure 2: Urban expansion and flood area in Ferizaj/Urosevac city. 
Considering the disaster probability and the impact, it is crucial to identify the vulnerability to flood and earthquake in Kosovo in order to achieve sustainable development. Ferizaj/Urosevac has been selected as a pilot city to examine the expansion of the vulnerable area in the urban area, which is triggered by the lack of disaster risk assessment and management in the perspective of spatial planning.

\subsection{Flood vulnerability}

Fig 2 shows the expansion of the built-up area in four different periods $(1965 / 1970 / 2000 / 2004)$ and the urban area is identified in the approved Ferizaj/Urosevac UDP. Adjacent to the city centre is one river, which is partly covered by residential roads and there is another river in the peri-urban interface in the south of the city. According to the municipal official in the department of emergency, the southern part of the city is often threatened by floods, particularly in spring time when snow from the mountains start melting down and flow into the river, overloading its capacity. In addition, people who do not live near the rivers do not hesitate to dump garbage in there and even construction companies also leave waste, which degrades the capacity of the rivers.

Looking back at flood records, there was one severe flood that struck the whole of the southern part of the city in 1973. Since then, floods have been limited to specific areas. However, some of these areas, which are shown in Fig 2, suffer from floods every year.

Following the trend of urban expansion before and after the severe flood in 1973, the built up area grew in an organic way along the main road network. Consequently, flood risk was not considered during urbanization, with some people even constructing housing within the flood prone areas.

The municipality drafted a plan for cleaning the river, but it has not been implemented due to the lack of municipal budget. On the other hand, the municipality have to allocate a budget for post-disaster relief when flooding happens every year, which indicates the lack of concept for the cost benefit.

\subsection{Earthquake vulnerability}

According to the municipal official in the department of urbanism, an archive of planning and construction permits exists from 1972 to 1991 and then there is no information regarding permits up to the end of the conflicts in the former Yugoslavia territory (1991-2000).

Before the conflict, building standards provided by the former Yugoslavia were applicable for building permits; however, after 1991 there were no substantive building standards that can be considered disaster resistant, such those that provide earthquake resistance. In 2004 the Law on Construction was promulgated that describes a new process for construction permits, although it does not contain the numerical standard. Moreover, the development control system is not functioning properly yet in Kosovo, which has brought a huge amount of illegal constructions to the city. Fig 4 shows an illegal construction 
with small concrete structures, which has a few walls on the ground floor that simply do not fulfil building standards for earthquake resistance. Moreover, Fig 5 shows illegal apartment flats built without adequate road infrastructure.

Illegal constructions have been continuously creating new vulnerable areas for an earthquake throughout the entire Kosovo territory and there are no remedies at this moment.

\section{Risk reduction strategy}

In Ferizaj/Urosevac municipality, the UDP was approved by the assembly in February 2009, which took a total of three years to prepare. In the drafting process, due to the lack of planning professionals in Kosovo, particularly in the

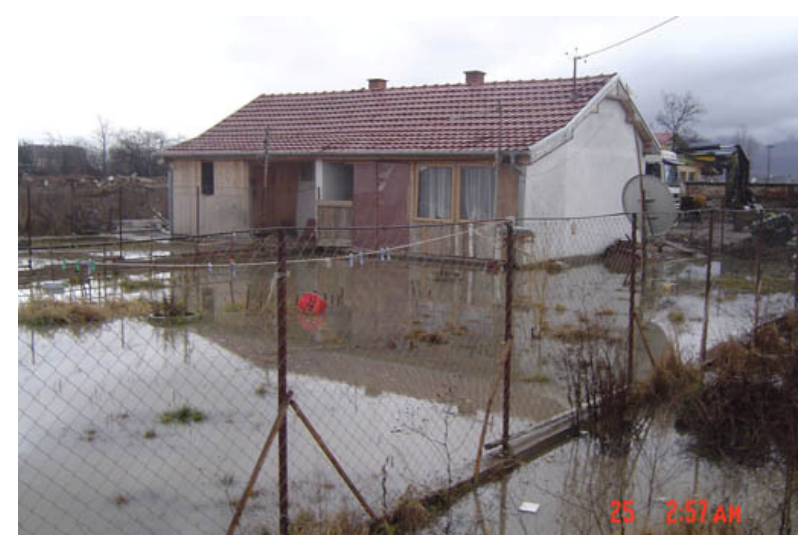

Figure 3: $\quad$ Flood prone area.

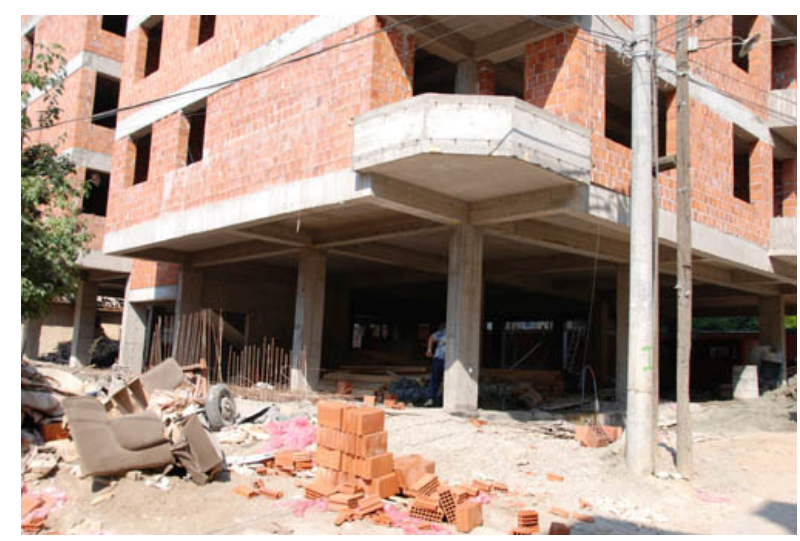

Figure 4: Vulnerable building structure (a typical illegal construction). 


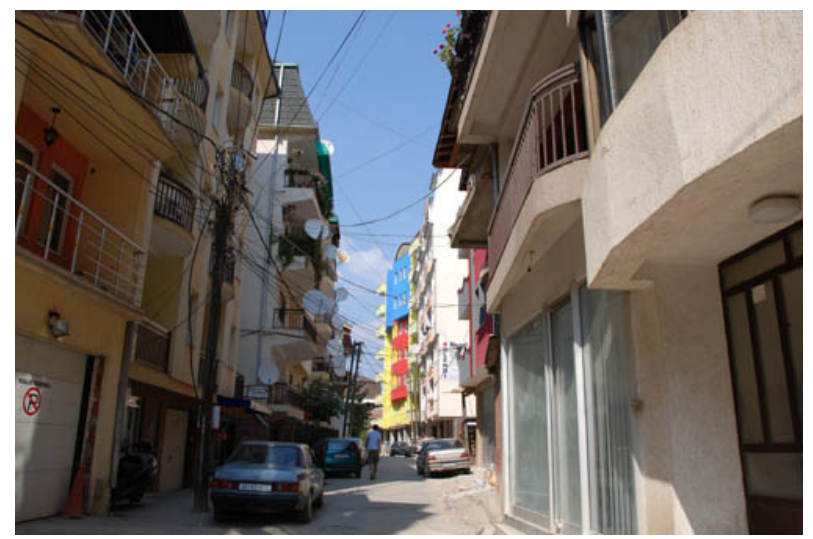

Figure 5: $\quad$ Earthquake vulnerable area.

public sectors, a consultant company was engaged by the municipal assembly for technical support. However, the company only submitted a full draft of the UDP with no consultation with the municipal officers. UN-HABITAT Kosovo was also meant to provide technical support and to stimulate public involvement in collaboration with the municipal officers. Consequently it only succeeded in the part of public participation in the planning process, but all ideas were not adequately reflected in the policy in the UDP. The municipality accepted the plan produced, even though it was not entirely adequate and it was decided to retrofit the UDP in some crucial components by the municipal officers in collaboration with UN-HABITAT.

Disaster risk assessment and management is one of the components to retrofit the adopted UDP. In compliance with the Spatial Plan of Kosovo as a national spatial plan, the UDP mentioned natural disaster risks in general, although no research and assessment of natural disaster risks were done by the company.

Fig 6 shows the risk reduction strategy that is intended to implement a new reservoir, which will be located downstream of the flood prone area. This proposal has background surveys concerning capacity, effectiveness, cost benefit, risk assessment, environmental impact assessment and feasibility.

\section{Inhabitants in the flood prone area}

Fig 2 indicates the relationship between the flood area and the urban expansion; new housings are still being constructed even on the flood prone area. The first preliminary survey has been done by UN-HABITAT in collaboration with the municipal officers to understand the behaviour of those people who select to live in the flood prone areas.

Two flood prone areas are identified for the survey area, where approximately 300 people live in total. Through the interviews around $80 \%$ of households replied to the questionnaire. 


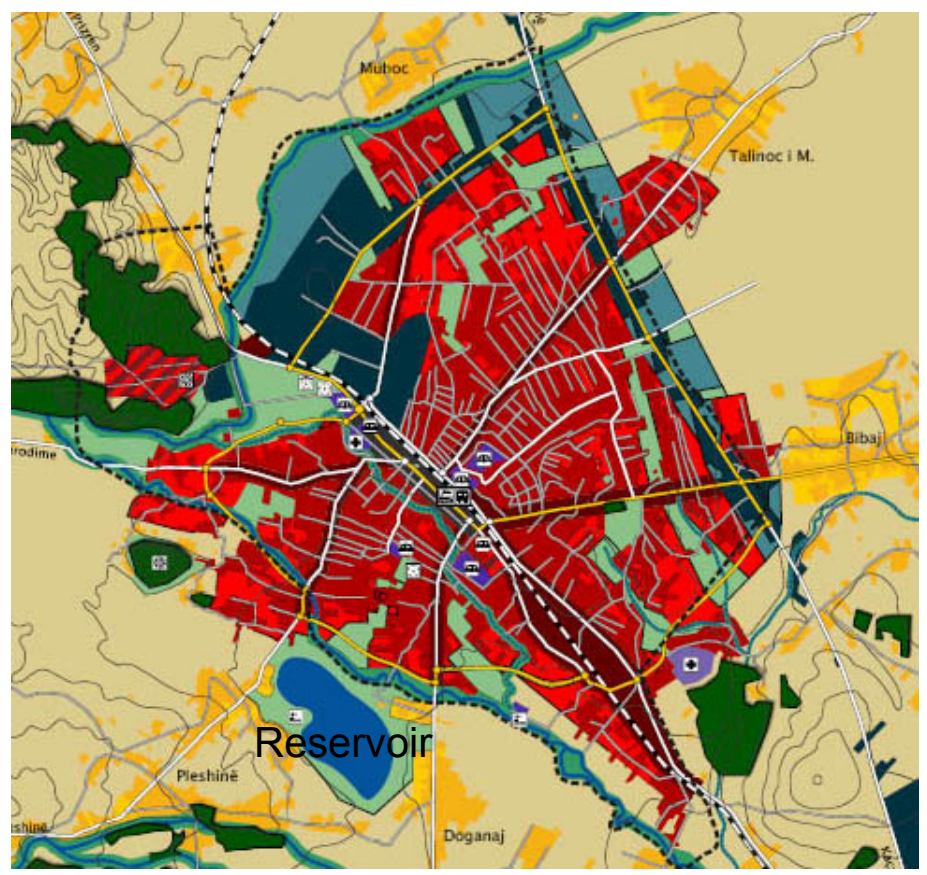

Figure 6: A reservoir designed for flood risk reduction in the UDP.

Table 1: $\quad$ Summary of the flood prone area survey.

\begin{tabular}{|cl|c|c|}
\hline & Survey area 1 & Survey area 2 \\
\hline 1. & Name of the city & Ferizaj/Urosevac & Ferizaj/Urosevac \\
\hline 2. & Number of houses & 128 & 192 \\
\hline 3. & Obtained answer & $100(78.7 \%)$ & $155(80.7 \%)$ \\
\hline 4. & Ethnic minorities & $1(1.0 \%)$ & $0(0.0 \%)$ \\
\hline 5. & Law income households & $36(36.0 \%)$ & $65(41.9 \%)$ \\
\hline 6. & Recognition of flood area & $77(77.0 \%)$ & $135(87.0 \%)$ \\
\hline 7. & Experience of floods & $63(63.0 \%)$ & $113(72.9 \%)$ \\
\hline 8. & Intention to stay & $86(86.0 \%)$ & $136(87.7 \%)$ \\
\hline 9. & $\begin{array}{l}\text { Desire to attend } \\
\text { discussions about flood }\end{array}$ & $71(71.0 \%)$ & $128(82.6 \%)$ \\
\hline 10. & $\begin{array}{l}\text { Desire to investment for } \\
\text { disaster prevention }\end{array}$ & $77(77.0 \%)$ & $125(80.6 \%)$ \\
\hline
\end{tabular}

\subsection{Economic aspects}

The primary assumption is that a person who lives in a flood prone area might be marginalized from society due to financial reasons or their ethnicity. It is quite difficult to obtain precise data of unemployment in Kosovo, but it is said to be approximately $60 \%$. Table 1 indicates around $40 \%$ of household heads below the average salary and we cannot say clearly that the households of those who live in 
the flood prone areas are more severely poor than those in other areas. Regarding ethnicity, the areas are dominated Kosovo-Albanian as the majority. Therefore, people do not live in the flood prone areas because they are marginalized from society.

\subsection{Desire for risk reduction and mitigation}

More than $80 \%$ of households experienced a flood; nonetheless $90 \%$ of them are hoping to stay in the same place. The families who live there do not strongly consider the risks and impacts on their life. In addition, $70-80 \%$ of households wish to attend the discussion for disaster risk reduction and mitigation and around $80 \%$ of households are willing to invest money for disaster prevention.

\section{Conclusions}

It is shown through the analysis of the Kosovo case that natural disasters not being a constant presence leads to ignorance, unconcern and negligence, which consequently cause expansion of the disaster vulnerable area. This is because disaster risks should be adequately assessed and be addressed, particularly in spatial planning, to give adequate advice to citizens in the process of development control. In the case of the highly vulnerable areas, new constructions should be restricted. The lack of substantive building and development standards also unconsciously enlarges the disaster vulnerable areas, particularly in the case of earthquakes. Formulation of adequate building and development standards should be discussed at national policy level and the development control system should also be strengthened.

Infusing the concept of disaster risk assessment, risk reduction and mitigation in the perspective of spatial planning is inevitable in order to achieve sustainable development, particularly in developing countries such as Kosovo. In the existing disaster prone there may be a high cost for post-disaster response and recovery to the government; therefore, the improvement cost should be compared with the cost of recovery after the disaster.

\section{References}

[1] Christine Wamsler, Mainstreaming risk reduction in urban planning and housing: a challenge for international aid organisations, Disasters: Overseas Development Institute, 30(2) pp151-177, 2006

[2] Souheil El-Masri \& Graham Tipple, Natural disaster, mitigation and sustainability: The case of developing countries, International Planning Studies: Carfax publishing, Vol.7 No.2 pp157-175, 2002

[3] Chennat Gopalakrishnan \& Norio Okada, Designing new institutions for implementing integrated disaster risk management: key elements and future directions, Disasters: Overseas Development Institute, 31(4) pp353-372, 2007 
[4] Ian Christoplos, John Mitchell \& Anna Liljelund, Re-framing risk: The changing context of disaster mitigation and preparedness, Disasters: Overseas Development Institute, 25(3) pp185-198, 2001

[5] Mark Pelling, Learning from others: the scope and challenges for participatory disaster risk assessment, Disasters: Overseas Development Institute, 31(4) pp373-385, 2007

[6] Fernando Aragon-Durand, Urbanisation and flood vulnerability in the periurban interface of Mexico City, Disasters: Overseas Development Institute, 31(4) pp477-494, 2007

[7] UN/ISDR and the World Bank, South Eastern Europe Disaster Risk Mitigation and Adaptation Initiative Risk Assessment for South Eastern Europe Desk Study Review, 2007 